\title{
123. LYCIUM FEROCISSIMUM MIERS EN LA PENÍNSULA IBÉRICA (MÁLAGA, ESPAÑA)
}

\author{
Andrés V. PÉREZ LATORRE, Rafael YUS RAMOS y Elías DANA SÁNCHEZ
}

\section{Lycium ferocissimum Miers in the Iberian Peninsula (Malaga, Spain)}

Palabras clave. Lycium, Solanaceae, plantas invasoras, Andalucía, España.

Key words. Lycium, Solanaceae, invading plants, Andalusia, Spain.

Málaga. Vélez-Málaga. Desembocadura del río Vélez. 30SVF0065. Setos sobre suelos de vega en cultivos abandonados. 12-05-2006. A. V. Pérez Latorre, G. Caballero y F. Soriguer. MGC 63799

Especie originaria de Sudáfrica que ha sido utilizada en zonas semiáridas y subtropicales de gran parte del planeta como creadora de setos y lindes. En muchos de estos países se considera una especie invasora muy difícil de erradicar. Se trataría de la primera cita para la Península Ibérica, al menos como especie naturalizada, con las localidades más cercana en Marruecos y una (posiblemente ornamental) en Guadalajara (Lambinon \& Lewalle, 1986).

Algunos datos de la población son los siguientes: casi un centenar de pies en buen estado, que florecen y fructifican con normalidad, con alturas entre 1 y 3 metros, situados en un parcela inculta sobre suelos de vega en un antiguo delta, en el piso bioclimático termomediterráneo inferior con ombrotipo seco. Actualmente la parcela presenta también vegetación ruderal y arvense y pastoreo de baja intensidad. Biogeográficamente la población de Lycium ferocissimum se localiza en el sector Malacitano-Axarquiense (provincia Bética, subregión Mediterránea Occidental) siendo la zonopotencialidad propicia para choperas de Vinco-Populetum albae (O. Bolòs \& Molinier 1958) O. Bolòs 1962.

La presencia de esta población completamente aislada nos hace suponer que fue inicialmente plantada hace algunos decenios como linde de la parcela minifundista donde se hallan. Se encontraron algunos ejemplares en las cercanías de esta parcela, pero han sido eliminados y formaban también parte de setos. Esto puede hacer pensar que en estos momentos L. ferocissimum no se está comportando como especie invasora, a pesar de la producción de gran cantidad de frutos y de la existencia de suelos fértiles. Otra hipótesis sería su importación por aves migratorias, ya que el delta del Vélez es zona de descanso para aves procedentes de África, aunque en este caso deberían aparecer ejemplares fuera de los setos, procedentes de la dispersión ornitócora.

AGRADECIMIENTOS. B. Cabezudo, M. Trigo, G. Caballero y F. Soriguer contribuyeron a la determinación final de este Lycium. F. Botella lo avistó por primera vez. J. Lambinon proporcionó datos corológicos.

\section{BIBLIOGRAFÍA}

LAMBINON, J. \& J. LEWALLE -1986- Lycium ferocissimum Miers. En: Notes brèves sur certaines centuries distribuées dans le fascicule 21. Soc. Ech. Pl. Vasc. Eur. Bass. Médit., 21: 49-70.

Aceptado para su publicación en octubre de 2006

Direcciones de los autores. A. V. Pérez Latorre: Departamento de Biología Vegetal, Universidad de Málaga. Apdo. 59, 29080 Málaga (España), avperez@uma.es; R. Yus: rafayus@telefonica.net. E.Dana: edana@ual.es. 